\title{
A SIMPLIFIED APPROACH FOR DETERMINING HYDROLOGIC BEHAVIOR AND DEPTH OF SOILS AT BASIN SCALE
}

\author{
Domenico Carriero, Nunzio Romano, Mauro Fiorentino
}

\section{Introduction}

Soil is a key component of the earth's biosphere, mainly because of its link between surface water and groundwater and the contact with the atmosphere. The hydraulic regime of soil governs the processes of storage and transmission of water and thus contributes greatly to the partitioning of rainfall into infiltration and overland flow. Many studies deal with the mathematical description of these basic hydrologic processes using models that differ in the complexity with which water flow in soil is described, partly depending on the spatial scale of interest. Correct parameterization of such processes is important when using mathematical models to derive threshold values for the splitting of runoff in its major components [19] or to estimate the spatial distribution of loss parameters during flood events when implementing regionalization techniques [8]. However, applications of these types of models are often intended over relatively large land areas and are thus limited by the required a huge quantity of quality data enabling the soil hydrologic response to be determined [28], [21].

Although at first sight soil processes seem to occur and being relevant at small scale only, there is evidence of their influence in assessing aggregated fluxes at larger scales [1], [15], [16], [30]. Some more difficulties also arise from the fact that accurate quantification of hydrologic fluxes requires specification of spatial, and sometimes also temporal, variability of model parameters, especially those characterizing soil from the hydraulic point of view.

Paper received 23.11.2005; accepted 22.03.2007

Domenico CARriero, PhD, Departement of Engineering and Environmental Physics (DIFA). University of Basilicata, Potenza (Italy). Referring e-mail: carriero@unibas.it.

Nunzio Romano, Professor of Agricultural Hydraulics, Department of Agricultural Engineering, Division for Land and Water Resources Management. University of Naples Federico II, Portici (Naples), (Italy).

Mauro Fiorentino, Professor of Hydraulic Construction, Department of Engineering and Environmental Physics (DIFA). University of Basilicata, Potenza (Italy).
Soil hydraulic properties are nonlinear relationships between the volumetric soil water content, $\theta$, the matric pressure head, $h$, and the hydraulic conductivity, $K$, which are commonly parameterized by the soil water retention, $\theta(h)$, and hydraulic conductivity, $K(\theta)$, functions.

The measurement of soil hydraulic properties with either direct methods or parameter optimization approaches is in general not easy and usually restricted to small-scale studies [24]. This is especially true when determining the soil hydraulic conductivity that not only shows a complex nonlinear dependence on matric pressure head, but also spans several orders of magnitude as soil conditions vary from saturation to dryness.

To overcome the above difficulties, simplified techniques are becoming increasingly popular that enable the soil hydraulic characteristics to be estimated from easily retrieved soil physical and chemical properties. These techniques are referred to in the literature as pedotransfer functions (PTFs) and usually are formulated in terms of multiple regression equations or within the framework of the artificial neural network theory [6].

One major limitation when using PTFs at basin scale is the availability of the input data at a sufficient number of locations within the area. On the one hand, sampling campaigns at that scale are rather unfeasible. On the other hand, pedological maps seldom provide all the input information required by PTFs (e.g. texture and organic matter content, but not bulk density). Therefore, other strategies, albeit simplified, need to be set up to cope with this challenging problem.

A starting point of this study is the well-known CLORPT (CLimate, Organism, Relief, Parent material, Time) model, which states that, at least in principle, a soil property can be derived from a relationship comprising such variables [14]. Following this track, Zhu et al. [31] developed a soil-land inference model (SOLIM) to predict soil properties distribution using four terrain attributes (elevation, aspect, slope gradient and profile curvature) with only two additional environmental variables (namely, lithology and vegetation) To simplify the assessment of water transport processes, Park et al. [23] proposed a Terrain Characterization 
Index (TCI), which is similar to Wetness Index (WI), $\mathrm{w}_{\mathrm{i}}=\ln (a / \tan \beta)$, where $a$ is the total upslope contributing area per unit contour length and $\beta$ is the local slope angle [2]. The wetness index reflects the tendency of water to accumulate at any point in the catchment (in terms of $a$ ) and the tendency for gravitational forces to move that water downslope (expressed in terms of $\tan \beta$ as an appropriate hydraulic gradient). The TCI index allows for land curvature and is related to soil depth, i.e. the hydrologically active zone of soil. Florinsky et al. [11] split a study area into three major parts depending on the relevant topographic attributes: accumulation zones, dissipation zones, and transit zones. This splitting makes easier the analyses of different hydrologic features and enables us to quantify the influence exerted by topographic attributes on soil depth and soil water content variations.

An interesting issue is to assess the influence of topography on the spatial distribution of vegetation, allowing also for the local climatic condition. In arid zones, for example, plant characteristics are strongly related to the zones of water fluxes convergence [10]. Moreover, with the diffusion of remote sensing, these relationships can be fruitfully retrieved by the Normalized Difference Vegetation Index, NDVI [13].

It has been shown that an efficient and cost-effective way to the soil hydraulic characterization over larger land areas is to add ancillary information from topography as well as to employ suitable spatial interpolation strategies to make predictions at unsampled locations [25], [27].

In this paper we propose a simplified technique to assess the soil thickness, which is viewed here as the hydrologically active part of soil, based on morphologic and vegetation information. We also explore the feasibility to describe the soil hydraulic property spatial distribution using the HYPRES (HYdraulic PRoperties of European Soil) database [29] and lithologic characteristics of the study area.

This approach is necessarily based on indirect estimation techniques and should be viewed as a tool to retrieve preliminary information on soil behavior in terms of soil hydrologic response and soil thickness. This is specifically of interest when applying certain types of rainfall-runoff models at relatively large scale. In fact, these types of hydrologic models do not often require comprehensive soil hydraulic characterization, but only those parameters enabling the identification of the main runoff components to be obtained (e.g. water content at saturation, or at the condition of field capacity, etc.).

\section{Study area and available data}

The study area is the Agri River basin (Basilicata Region, Italy), having a drainage area of approximately $1770 \mathrm{~km}^{2}$ and a river length of approximately 136 $\mathrm{km}$. The basin has a stretched shape mainly in the East-West direction.
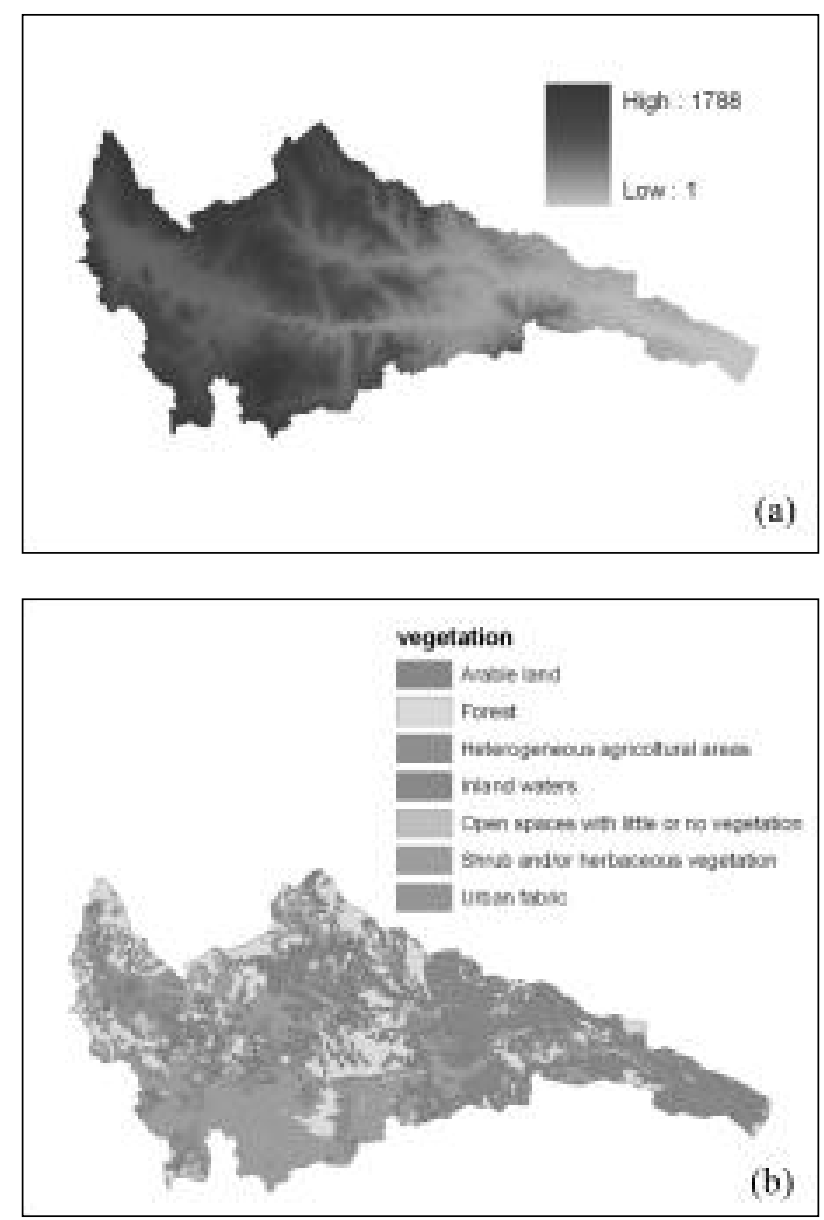

Fig. 1 - Topography (DEM $240 \times 240 \mathrm{~m}$ ) (a), and vegetation coverage (CORINE $2^{\text {nd }}$ level, scale 1:100.000) (b) for the Agri River Basin.

Data used in this investigation are retrieved from a Digital Elevation Model (DEM), with cell size of $240 \times 240 \mathrm{~m}$, and a land cover map (CORINE) according to the $2^{\text {nd }}$ classification level (see Figure $1 \mathrm{a}$ and $1 \mathrm{~b}$, respectively). The DEM enabled the computation of major terrain attributes, such as slope angle, slope orientation (aspect), and wetness index (Figure 2).

Basic climatic features have been obtained from the spatial distribution of the mean annual precipitation (Figure 3a) and the Budyko dryness index (Figure $3 \mathrm{~b})$. The Budyko index is given from $R_{n} /(\lambda \cdot P)$, where $R_{n}$ is the mean annual net radiation, $\lambda$ is the vaporization latent heat, and $P$ is the mean annual precipitation [5]. Specifically, areas with a Budyko index of about 1 or lower are defined as humid, whereas higher values are to be associated to more intense evaporation phenomena, hence to mainly dry areas.

Based on previous physical and economical studies [12], the entire Agri River basin is usually partitioned into three different parts as follows (see Figure 4): the Upper Agri Basin, with a predominance of forest and a very humid climate; the Lower Agri Basin, which is rather dry and shows the presence of agricultural lands; the Middle Agri Basin, which can be viewed as a sort of transition zone between the previous ones.

The following major lithologic formations are iden- 

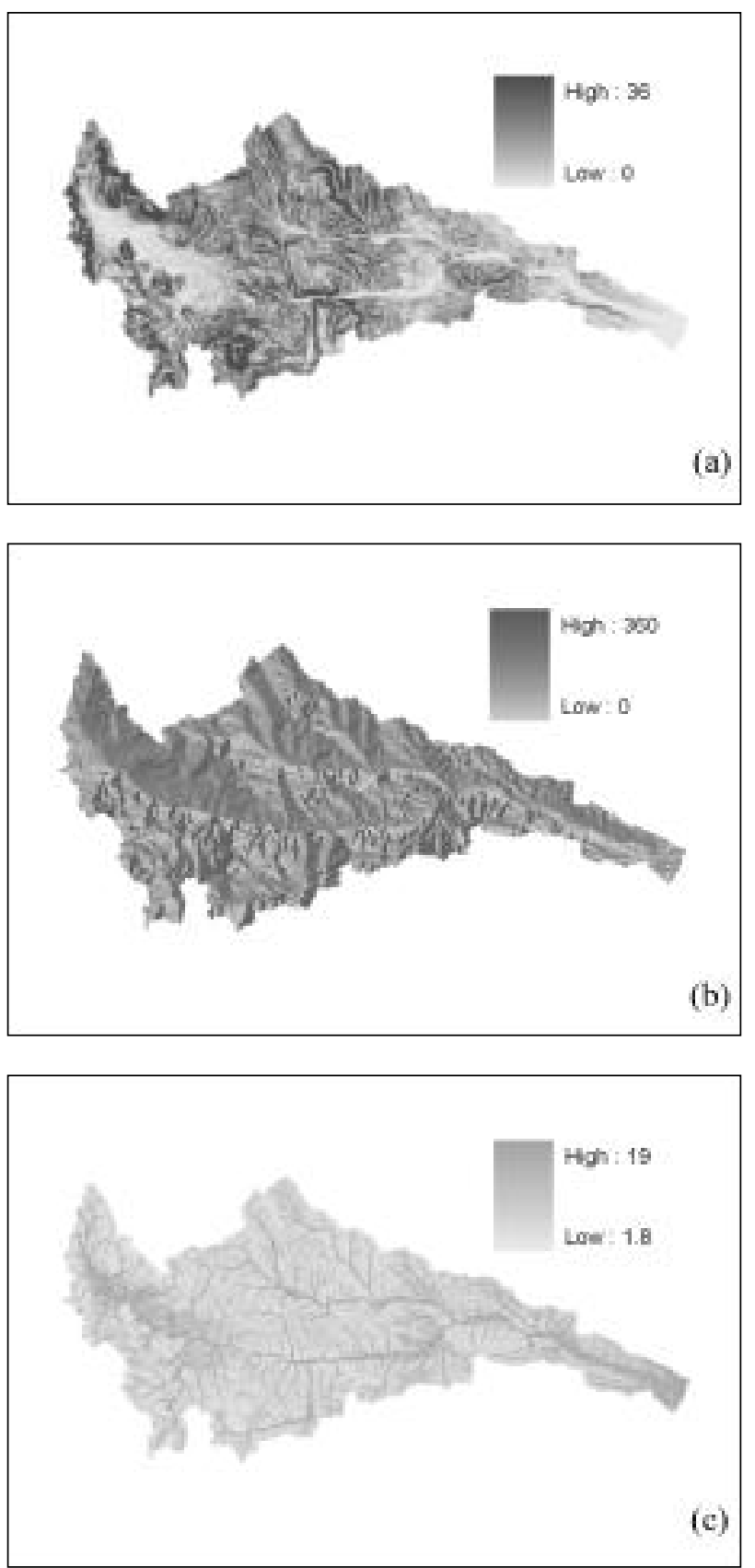

Fig. 2 - Primary and secondary terrain attributes for the Agri River Basin as derived from the available DEM $(240 \times 240 \mathrm{~m})$ : (a) slope, (b) aspect, and (c) wetness index.

tified within the above three different parts of the basin: carbonatic rock and detritus in the Upper Agri Basin; Gorgoglione formation (sandstone), sands and conglomerates in the Middle Agri Basin; grey-blue clays and alluvial plains in the Lower Agri Basin. Other information is retrieved from the lithologic map of the Basilicata Region, developed by the Research Unit No. 1.21 of the National Group for Prevention from Hydro-Geological Disasters (GNDCI) (Figure 5).

Key soil physical characteristics for the application of hydrologic models over large land areas are texture and depth of soils. Soil texture can be represented by the contents in sand, silt, and clay particles. Accord-
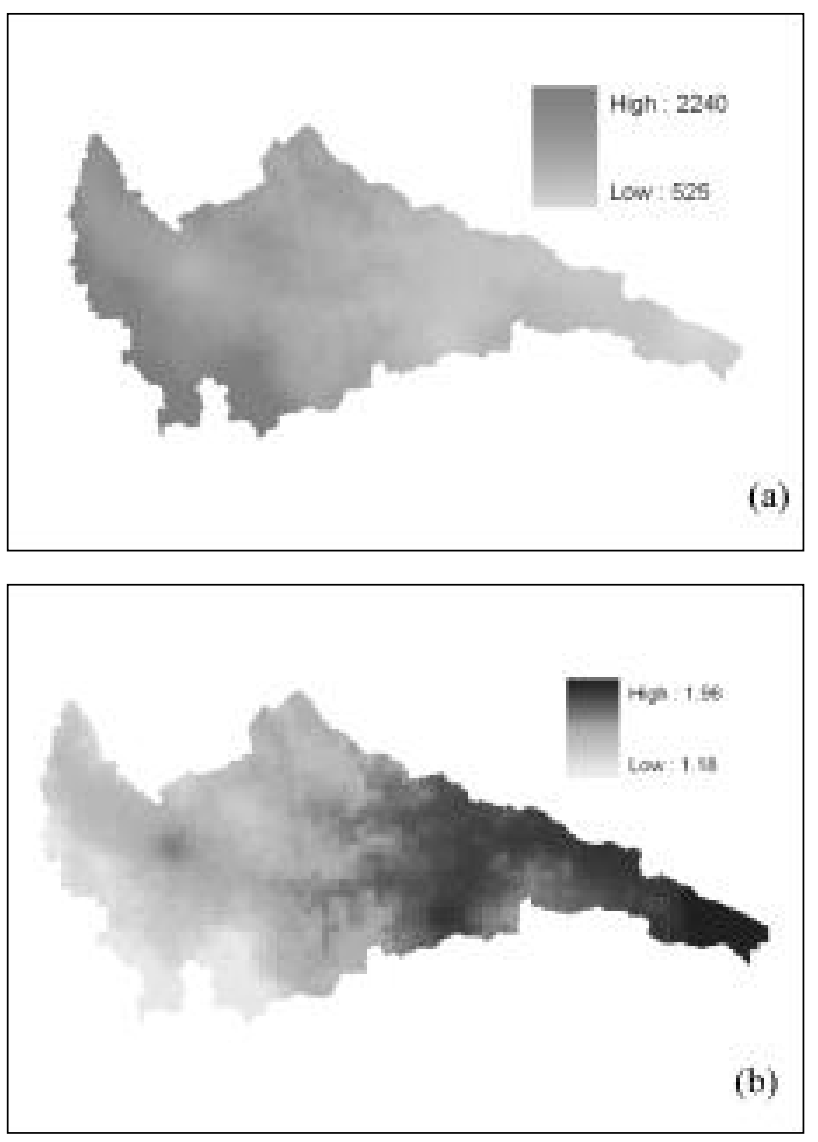

Fig. 3 - Climatic characteristics (grid $1 \times 1 \mathrm{~km}$ ) for the Agri River Basin: (a) mean annual precipitation, (b) Budyko index.

ing to a classic pedological view, soil depth is the depth of soil to bedrock or to a restricted layer. In this study we consider the soil depth as the total thickness of the A and B soil horizons. In general soil depth is the depth to which plant roots develop and determines how deep water and air can penetrate into a soil profile. Therefore, in turn, it influences how much water can infiltrate or can be held in it. Soil depth is thus important for determining the amount of runoff.

Soil physical data have been retrieved from the Land System Map of the Agri basin, developed by the CNR (National Research Council of Italy) research

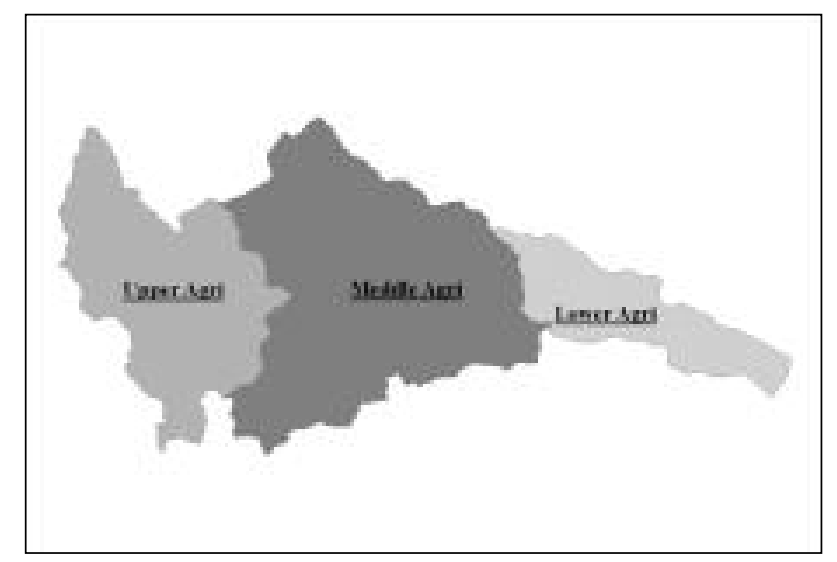

Fig. 4 - Major sub-basins of the Agri River Basin. 


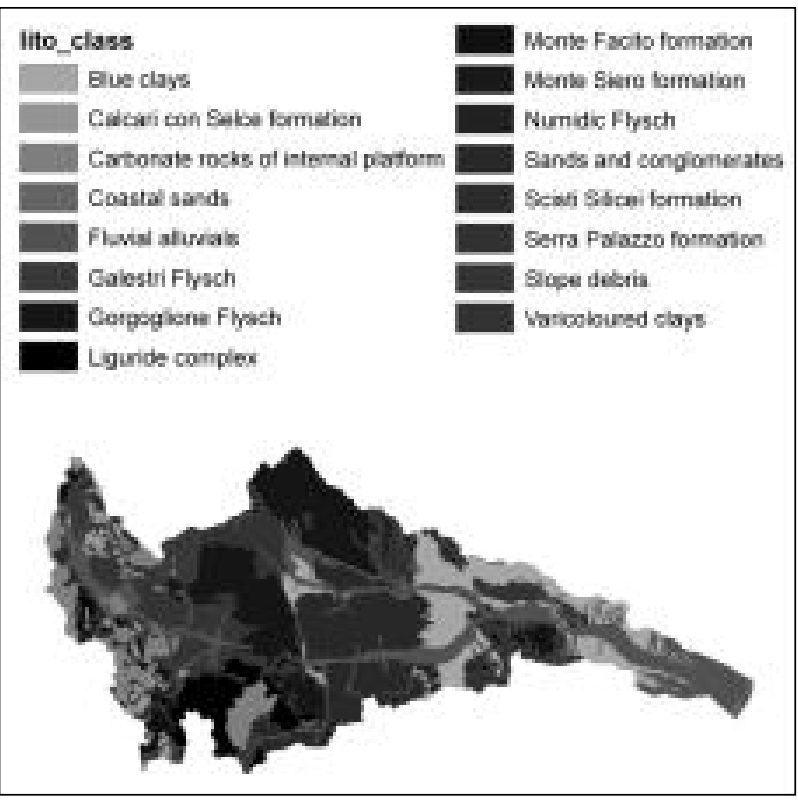

Fig. 5 - Lithologic map of the Agri River Basin (1:250.000).

unit in Florence [4]. This map provides textural information according to the FAO classification system, but gives only qualitative information about soil depths in terms of major groups (i.e. deep soil, not much deep soil, etc.).

In the present study, we have validated the CNR Land Systems map using high resolution soil maps (at the scale 1:25.000) produced by Basilicata Region agency.

First, this validation phase has been employed to obtain quantitative information about soil depth. The outcome of this task is synthesized in Table 1 .

Moreover, the validation phase also enabled us to test the reliability of the CNR map at the scale of interest and to transfer the FAO data into the textural classification system utilized by the HYPRES database (see Table 2). The major features of this European database will be presented in the next section.

\begin{tabular}{lcc}
\hline \multicolumn{1}{c}{ Soil-depth class } & \multicolumn{2}{c}{ Soil thickness $(\mathrm{cm})$} \\
& range & mean value \\
\hline Very shallow & $<20$ & 10 \\
Shallow & $20-50$ & 35 \\
Moderately deep & $50-100$ & 75 \\
Deep & $100-150$ & 125 \\
Very deep & $>150$ & 180 \\
\hline
\end{tabular}

TABLE 1 - Soil-depth classes and related thickness for the Agri River Basin.

\begin{tabular}{cc}
\hline Name & Definition \\
\hline coarse & clay $<18 \%$ and sand $>65 \%$ \\
medium & $\begin{array}{c}18 \%<\text { clay }<35 \% \text { and } 15 \%<\text { sand } \\
\text { or clay }<18 \% \text { and } 15 \%<\text { sand }<65 \%\end{array}$ \\
medium fine & clay $<35 \%$ and sand $<15 \%$ \\
\hline fine & $35 \%<$ clay $<60 \%$ \\
veryfine & $60 \%<$ clay \\
\hline
\end{tabular}

TABLE 2 - The HYPRES soil texture classification system.

\section{Use of the HYPRES database for predicting soil hydraulic properties}

In this study we describe the soil water retention, $\theta(h)$, and hydraulic conductivity, $K(\theta)$ functions using the following van Genuchten's relations [17]:

$$
\begin{aligned}
& \theta(h)=\theta_{r}+\left(\theta_{n}-\theta_{r}\right)\left[1+(\alpha h)^{r}\right]^{-\infty} \\
& K(h)=\frac{K,\left\{1-(\alpha h)^{-v}\left[1+\left(\alpha h^{n}\right)\right]^{-=}\right\}}{\left.1+(\alpha h)^{r}\right\}^{-v}}
\end{aligned}
$$

where $\theta_{s}$ and $\theta_{r}$ are the saturated and the residual water content, respectively, $\alpha, m$ and $n$ are shape parameters, and assuming $m=1-1 / n, K_{s}$ is the hydraulic conductivity at saturation, and $v$ is a tortuosity coefficient, which is often set at 0.5 .

For hydrologic applications that utilize the soil water retention and hydraulic conductivity functions, the reference to the HYPRES database and its textural classification system is advantageous as it makes easier the soil hydraulic characterization. That ease is chiefly because the HYPRES database provides the parameters that identify van Genuchten's soil hydraulic function (1)-(2) for different textural classes (see Table 3).

\begin{tabular}{cccccccr}
\hline Texture & $\theta_{r}$ & $\theta_{s}$ & $\alpha$ & $n$ & $m$ & $l$ & \multicolumn{1}{c}{$K_{s}$} \\
\hline \multicolumn{7}{c}{ Topsoils } \\
coarse & 0.025 & 0.403 & 0.038 & 1.377 & 0.274 & 1.250 & 60.00 \\
medium & 0.010 & 0.439 & 0.031 & 1.180 & 0.153 & -2.342 & 12.06 \\
medium fine & 0.010 & 0.430 & 0.008 & 1.254 & 0.203 & -0.588 & 2.27 \\
fine & 0.010 & 0.520 & 0.037 & 1.101 & 0.092 & -1.977 & 24.80 \\
very-fine & 0.010 & 0.614 & 0.027 & 1.103 & 0.094 & 2.500 & 15.00 \\
& \multicolumn{7}{c}{ Subsoils } \\
coarse & 0.025 & 0.366 & 0.043 & 1.521 & 0.342 & 1.250 & 70.00 \\
medium & 0.010 & 0.392 & 0.025 & 1.689 & 0.145 & -0.744 & 10.76 \\
medium fine & 0.010 & 0.412 & 0.008 & 1.218 & 0.179 & 0.500 & 4.00 \\
fine & 0.010 & 0.481 & 0.019 & 1.086 & 0.079 & -3.712 & 8.50 \\
very-fine & 0.010 & 0.538 & 0.017 & 1.073 & 0.068 & 0.000 & 8.24 \\
\hline
\end{tabular}

TABLE 3 - Soil hydraulic parameter values of van Genuchten's relations (1) and (2) as provided by the HYPRES database $\left(\alpha\right.$ in $\mathrm{cm}^{-1}, K_{s}$ in $\left.\mathrm{cm} / \mathrm{d}\right)$.

However, with a view to simplifying the description of water movement in soil under field conditions, some hydrologic models rely on a functional parameterization of soil hydraulic behavior by using the socalled soil water holding characteristics; for example, the field capacity value [7]. Field capacity is often assumed as the water content value in a uniform soil profile at which the redistribution process, following an infiltration event, proceeds so slowly that draining rates becomes virtually negligible. Although this variable should be viewed as a process-based parameter being determined using specifically-designed field ex- 
periments, it is often associated to a specific point of the soil water retention function, specifically the water content at the matric pressure head of $h=-330 \mathrm{~cm}$ or $h=-50 \mathrm{~cm}$. The latter water retention value has been selected by HYPRES to identify a field capacity condition in field soils.

\section{Methods and results}

\subsection{Estimating soil depth}

As mentioned, soil depth and texture are important soil physical characteristics for parameterizing hydrologic processes at relatively large scales. For example, they are utilized in capacitance-type hydrologic models to compute surface runoff and evaporative fluxes [18].

From a functional point of view, a soil profile is often partitioned in topsoil and subsoil, with topsoil ranging from 0-30 cm and subsoil ranging from $30-100 \mathrm{~cm}$. Soil formation and development are the result of a number of physical processes involving several factors. Among these factors, precipitation and subsequent water movement over different landform elements exerts a remarkable influence on soil profile features. These phenomena are also affected by plant coverage that intercepts raindrops, provides a protective cover of leaf litter, binds soil with roots, and decreases runoff velocity. Topographic attributes and vegetation cover affect soil moisture in the uppermost soil horizons as they exert some influence on infiltration [11].

Such considerations lead us through the search for possible correlations between the spatial distribution at basin scale of our available information (namely, topography, climatic characteristics, vegetation, lithology, etc.) and the parameters of soil thickness and texture.

We carried out an analysis based on a superimposing of geographic information images, which are discretized into grids with cells of the same size $(240 \times 240 \mathrm{~m})$. The maps of the dependent variables (i.e. soil thickness and texture) were superimposed, respectively, to maps of topographic attributes (altitude, slope gradient, slope orientation, wetness index), climatic attributes (mean annual precipitation, dryness index), lithology, and vegetation. In a subsequent

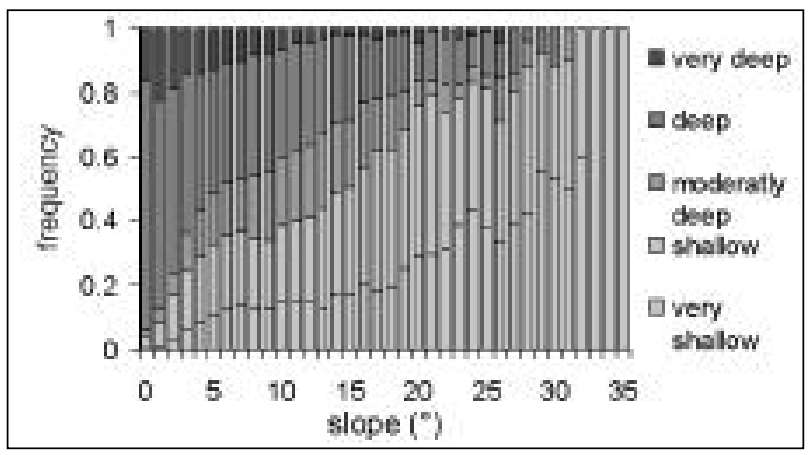

Fig. 6 - Frequency distribution of soil depth classes as a function of slope angles. more in-depth analysis, allowing for these previously obtained outcomes, the spatial distribution of soil depth was compared with combinations the available maps of the basin attributes.

The results obtained are synthesized here by the frequency distributions of the two dependent variables (texture and thickness) as a function of the already cited available data. For the sake of brevity, in the following, we shall illustrate and discuss cases only for a few basin hydrologic attributes.

Figure 6 shows the relationship between soil depth classes and slope angle. The magnitude of the gravity force component parallel to the ground, which is greater where slope is steeper, hinders the accumulation of material and consequently the formation of deep soils because of the increasing in overland flow velocity. Therefore, the likelihood of the spatial occurrence of deeper soils is greater on milder slopes, whereas the likelihood of the spatial occurrence of thinner soils is greater on steeper slopes. In general, soil depth decreases as slope angle increases.

We employed classic statistical tools to identify possible relationships between soil thickness and some combined variables. A very interesting outcome is the influence exerted by vegetation cover and slope angle on soil thickness. As mentioned before, the information about vegetation cover for the study basin has been retrieved using the Corine Land Cover Map. The plots in Figure 7 synthesize these findings.

Looking at the plots of Figure 7 horizontally (namely, plots 7a-d, 7b-e, or 7c-f), namely moving from "moderately deep" to "very deep" soils but with vegetation cover being equal, a shift occurs in the peak of the frequency distribution toward the lower values of slope angle. Therefore, this result confirms that the previously found relation depicted in Figure 6 should hold also in those zones with a fairly homogeneous vegetation coverage.

Instead, moving up and down among these plots following a vertical direction (i.e. plots $7 \mathrm{a}-\mathrm{b}-\mathrm{c}$, or $7 \mathrm{~d}-\mathrm{e}-\mathrm{f}$ ), means that vegetation cover is changing with soil depth being equal. In this case, a shift of the peaks in the frequency distribution occurs toward the lower values of slope angles when moving from the wood lands to the arable lands, i.e. moving toward vegetation types that are characterized by less complex root systems.

In other words, for very deep soils (i.e. see plots $7 d-e-f)$ the frequency distribution analysis shows that at higher slope angles it is more likely to find deep soils with woods than with arable lands. The same would apply in the case of shallow soils (see plots 7ab-c). This latter outcome can be explained by noting that vegetation with more complex root systems (for example, that one of woods) binds deeper soils also on steeper hillsides.

\subsection{Estimating soil texture}

For either the entire Agri basin or its three different sub-basins, rather weak correlations have been detect- 
shallow soils
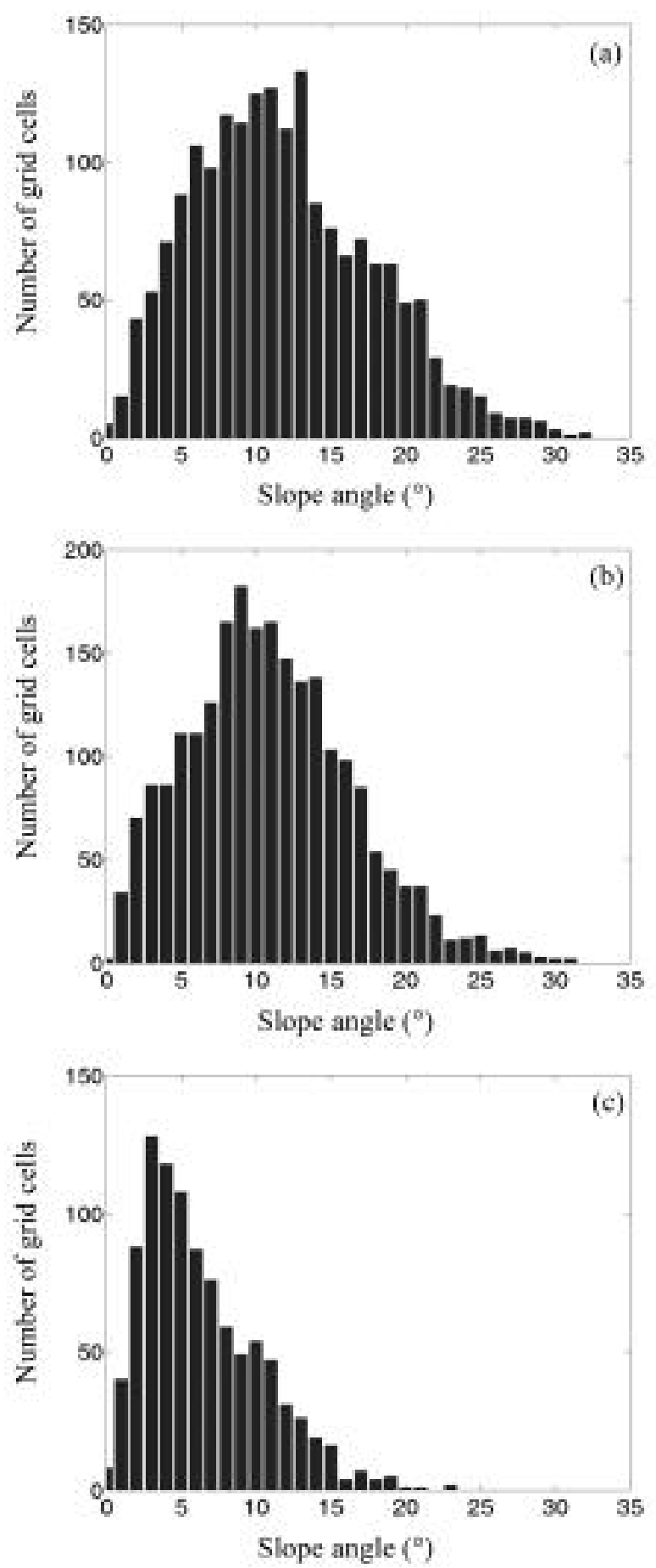

wery deep soils
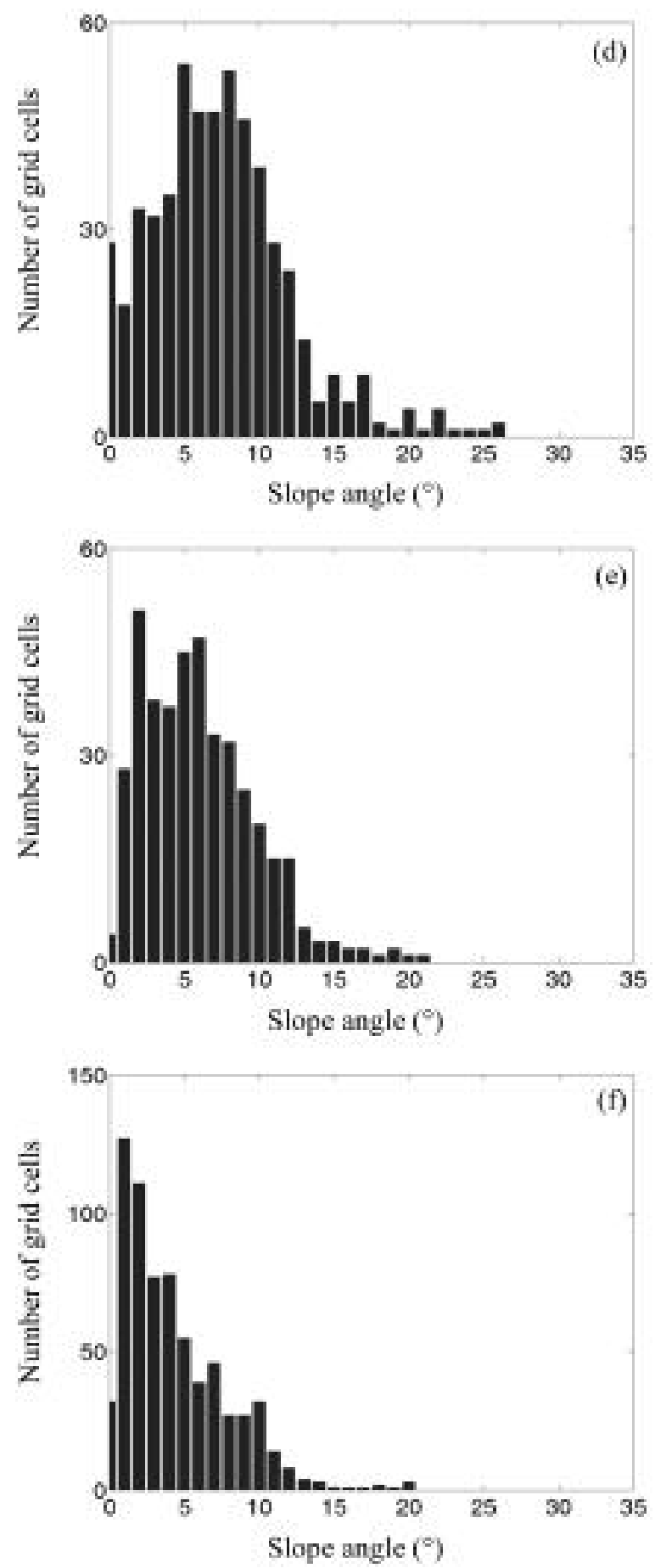

Fig. 7 - Frequency distribution of slope angles for different soil depth classes (a-b-c, shallow soils; d-e-f, very deep soils) and vegetation coverage (a-d, woods; b-e, shrubs; c-f, arable lands).

ed between soil texture and some basin morphologic characteristics. This can be partly attributed to the relatively low resolution of the available DEM $(240 \times 240$ m) utilized in this study to retrieve the morphologic attributes (slope gradient, slope orientation, etc.). Unfortunately, a higher resolution DEM was not available and therefore we have been unable to evaluate the uncertainty being associated to these outcomes.
However, as expected and discussed in the literature, lithology exerts some influence on soil texture. For two differently zones classified as alluvium and greyblue clays, Figure 8 depicts the most frequent textural classes, which have been obtained with the previously mentioned superposition of the available maps. Plot 8 a shows that coarse-textured soils are more likely to occur within alluvium zones, whereas plot $8 \mathrm{~b}$ shows 


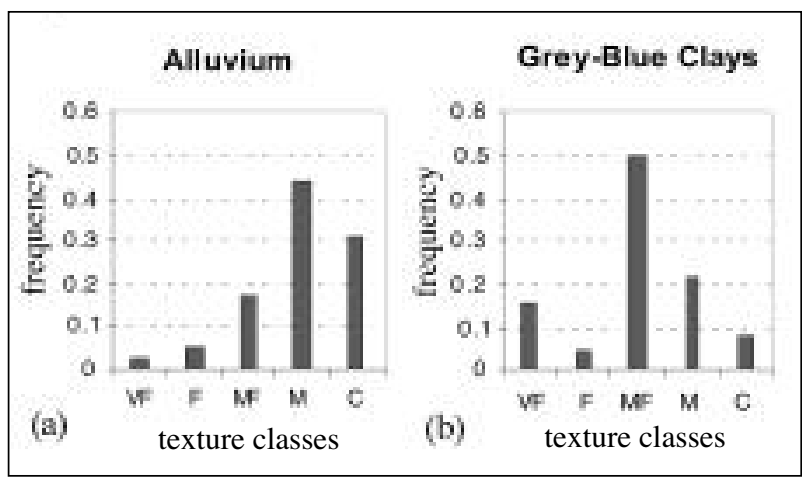

Fig. 8 - Frequency distribution of the HYPRES soil textural classes (VF, very fine; F, fine; MF, medium-fine; $\mathrm{M}$, medium; $\mathrm{C}$, coarse) for two different lithological classes: (a) alluvium, (b) grey-blue clays.

that if the lithology is grey-blue clays then there is a predominance of soils with finer materials (i.e. $\mathrm{MF}$ soils).

\subsection{Mapping soil physical and hydraulic characteri-} stics at basin scales

The relationships obtained and discussed in the previous sections can be viewed as a soft tool to estimate the major soil parameters being then used as input in hydrologic models [3].

With a view to showing an application of such relations at a regional scale, Figure 9 shows the spatial distribution of soil depths for the basins of Basilicata

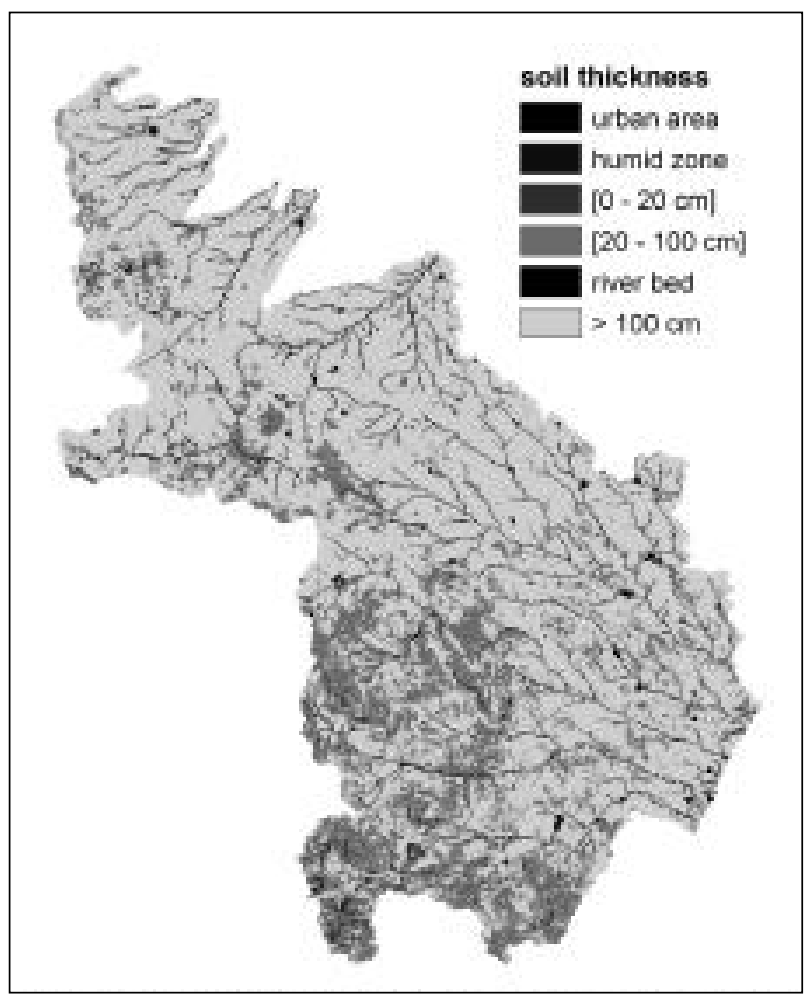

Fig. 9 - Spatial distribution of soil depth over the major basins of Basilicata and Puglia Regions (Southern Italy) as estimated by the proposed method. and Puglia Regions. These soil depths are grouped into three major classes and have been estimated using the results depicted in Figure 7.

Another application begins using a lithological map (at the scale 1:250.000) and proceeds by assigning to every lithologic unit the corresponding soil textural class. The textural classes are identified by the median value of the statistical distributions shown in Figure 8 for the study basin. The use of the HYPRES database and the related class-ptf allows the determination of the parameters that associate the soil hydraulic properties to each class (see Table 3 ).

As some hydrologic models employ the bucket concept and use the field capacity value to synthesize the water storage ability of field soils, Figure 10 is a map of the soil water retention value $\theta(h=-50 \mathrm{~cm})$, which is assumed as field capacity value according to HYPRES, using the parameters in Table 3.

\subsection{Further considerations}

The results showed in the previous sections refer to the entire study area of the Agri basin. Analyses performed at sub-basin levels allow further consideration on the variables that mainly affect the determination of soil thickness. We carried out this task with the specific objective of examining whether suitable correlations can be identified within each of the three Agri River sub-basins (i.e. the Upper, Middle, and Lower Agri Basin). A dependence of soil depth on wetness index and mean annual precipitation has been

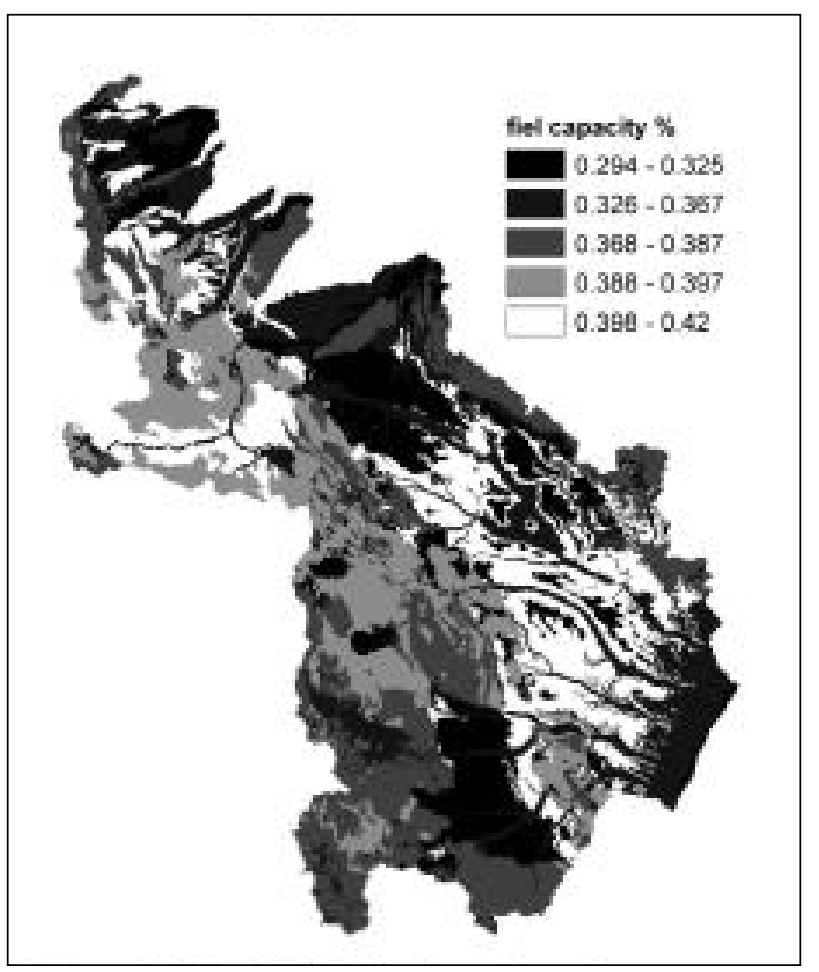

Fig. 10- Spatial distribution of $\theta_{-50}$, i.e. water content, $\theta$, at matric head $h=-50 \mathrm{~cm}$ (field capacity according to HYPRES), for the topsoil over the major basins of Basilicata and Puglia Regions (Southern Italy) as estimated by the proposed method. 


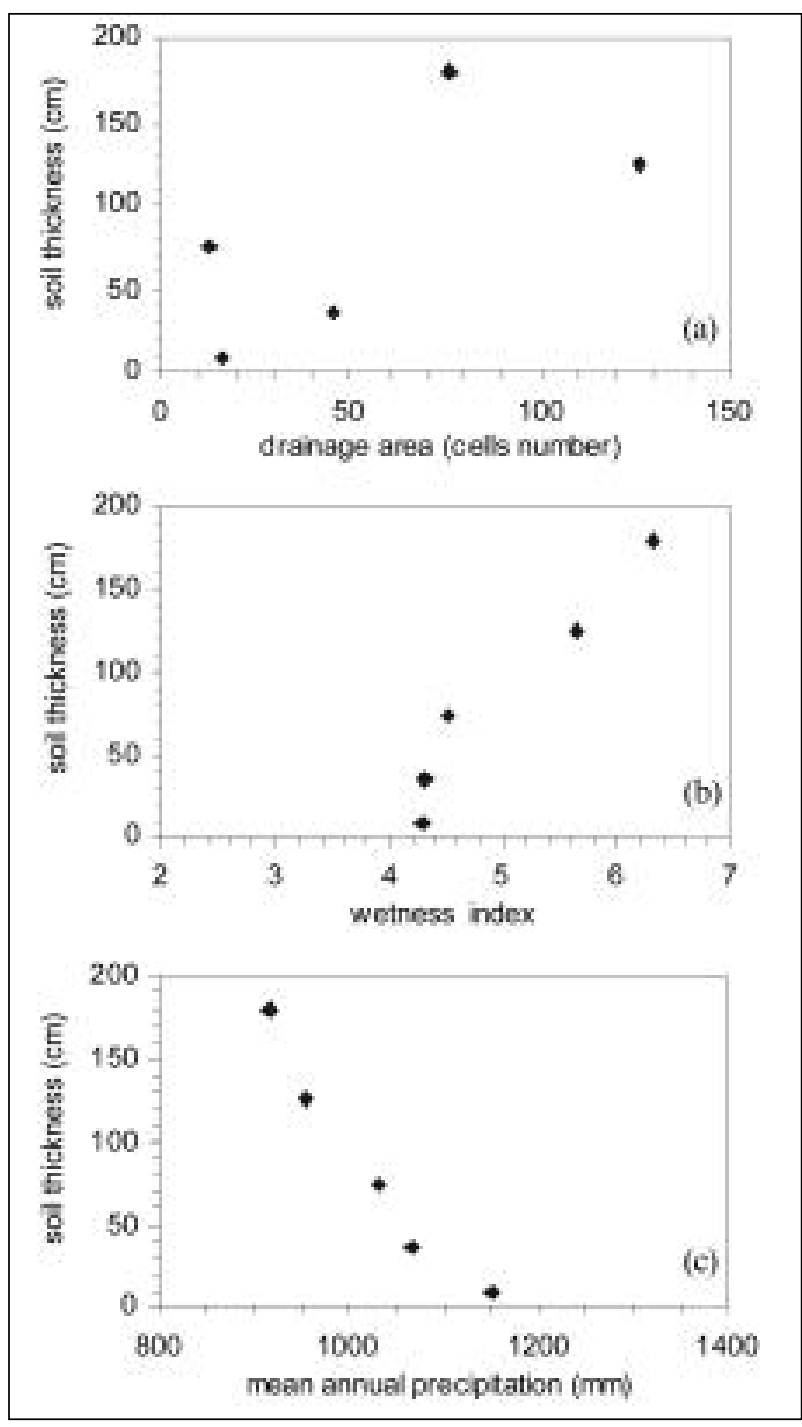

Fig. 11 - Drainage area (a), wetness index (b) and mean annual precipitation (c) as function of soil depth for the Upper Agri Basin.

found for the data pertaining to the Upper Agri Basin (see Figure $11 \mathrm{~b}$ and c). These results can be viewed in a unified manner as they are somewhat linked to the mechanism of transportation of soil materials, in both suspension and solution, over the soil surface or within the soil by vertical and lateral soil water flows. The higher the rainfall, the greater the hill-washed materials. This process occurs chiefly at zones characterized by larger upslope contributing areas combined with lower slope gradient values (i.e. greater wetness index, WI, values). This would justify the observed trend of increasing soil depth as WI increases.

With a view to analyze separately the behavior of each morphologic attribute that contributes to parameter WI, i.e. the upslope contributing area and slope gradient, Figure 11a illustrates that the upslope contributing area does not exert a remarkable influence on soil thickness. A possible reason for this feature, which occurs in a specific part of the basin, can be the relatively large variability in climatic and morphologic characteristics. In the Upper Agri Basin the mean annual precipitation varies from $1,000 \mathrm{~mm}$ to 2,200 $\mathrm{mm}$, whereas morphology shows marked slope dissimilarities with very steep lands in the highlands and relatively large flat areas in the valleys. The sharp splitting between these zones would reflect on the processes of material transportation, and hence on soil thickness development.

\section{Conclusions}

In this paper we have implemented a simplified approach for evaluating some key soil physical and hydraulic parameters. An interesting aspect of the proposed approach is the use of vegetation characteristics as ancillary input variables to refine the correlations between basin morphologic attributes and soil physical characteristics.

Regression pedotransfer functions are powerful tools in estimating soil hydraulic properties and prove fairly efficient also in assessing the spatial patterns exhibited by these properties [26]. However, when spatial variability is relatively high over a region of interest and a large number of samples are required to characterize it, providing input information to PTFs can even be a difficult and costly task.

The first outcome of this study concerns the indirect estimation of soil texture and depth. A fairly good correlation has been detected for the study basin between soil depth and slope gradient. This correlation can be improved if information about vegetation characteristics is added. For zones of the basin with similar values of soil thickness, a difference in vegetation coverage affects the frequency distribution of slope gradients. Soil depth also appears fairly well correlated to some morphologic and climatic attributes, such as the wetness index and mean annual precipitation.

Soil texture has been classified here according to the HYPRES project and shows rather weak or absence of relationship to morphologic attributes, at least at the resolution of the maps utilized in this work. Soil texture has a dependence with the parental lithology.

When working at large basin scales, the relationships among ancillary data and soil physical properties can be suitably exploit to gain an initial picture of the spatial distribution of soil hydraulic properties, especially in those not yet sampled areas. The maps of Figure 9 and Figure 10 should be viewed here only with the major aim of showing an application of the relationships retrieved in this study. These maps provide basic information that can be then useful for gaining preliminary hydrologic predictions in ungauged basin (PUB) [9]. This issue is now receiving considerable attention from scientists and engineers and the method presented in this paper should be viewed as a contribution to obtain better predictions of the hydraulic behavior of soils, still at reasonable costs in terms of both time and money with respect to the extend of the area of interest. 


\section{References}

[1] ARrigo J.A.S., SAlvUCCI G.D., Investigation hydrologic scaling: Observed effects of heterogeneity and nonlocal processes across hillslope, watershed, and regional scales, Water Resour. Res., (2005) 41, W11417, doi:10.1029/ 2005WR004032.

[2] BeVEn K.J., KIRKBY M.J., A physically-based variable contributing area model of basin hydrology, $\mathrm{Hy}-$ dral. Sc. Bull (1979), 24(1), pp. 43-69.

[3] Carriero D., Laguardia G., Romano N., Analisi dell'influenza delle caratteristiche del suolo sul bilancio idrologico di un bacino, VIII Convegno Nazionale di Ingegneria Agraria, (2005) ISBN 88901860-0-3, Edited by GeoGrafica-Catania.

[4] Catizzone M., Carta dei Land System del bacino del F. Agri (PZ e MT), scala 1:100.000, C.N.R. Centro di studio per la genesi, cartografia e classificazione del suolo, (1979) Firenze, pubbl. n. 60.

[5] Claps P., Mancino L., Impiego di classificazioni climatiche quantitative nell'analisi regionale del deflusso annuo, $28^{\circ}$ Convegno Nazionale di Idraulica e Costruzioni Idrauliche, (2002) Potenza, Vol.1, pp. 169-178.

[6] Elsenbeer H., Preface of the special issue on pedotransfer functions in hydrology, Journal of Hydrology (2001), 251:121-122.

[7] Farmer D.F., Sivapalan M., JothityangKoon C., Climate, soil and vegetation controls upon the variability of water balance in temperate and semi-arid landscapes: downward water balance analysis, Water Resour. Res. (2003) Vol. 39, No.2, p. 1035.

[8] Fiorentino M., Carriero D., Laguardia G., MaNFreda S., Margiotta M., Rosano R., Sole A., IacoBELLIS V., Una proposta metodologica per la mappatura della variabilità spaziale delle perdite idrologiche durante $i$ fenomeni di piena, Convegno Nazionale sulla Conservazione dell'ambiente e rischio idrogeologico, Assisi (2002), 11-12 dicembre.

[9] Fiorentino M., Carriero D., Iacobellis V., ManFREDA S., PORTOGHESE I., "MEDCLUB -starting line and first activities", In: Predictions in Ungauged Basins: Promises and Progress edited by Sivapalan M., Wagener T., Uhlenbrook S., Zehe E., Lakshmi V., Liang X., Tachikawa Y. \& Kumar P., (2006) ISBN 1901502-48-1, IAHS Publ. 303.

[10] Florinsky I.V., Kuryakova G.A., Influence of topography on some vegetation cover properties, Catena (1996), 27:123-141.

[11] Florinsky I.V., Eilers R.G., Manning G., Fuller L.G., Prediction of soil properties by digital terrain modelling, Environmental Modelling and Software, (2002) 17: 295-311.

[12] Geeson N.A., Brandt C.J., Thornes J.B., Mediterranean Desertification: A mosaic of processes and responses, John Wiley \& Sons Ltd (2002), Chichester, UK

[13] Hengl T., Rossiter D.G., Husnjak S., Mapping soil properties from an existing national soil data set us ing freely available ancillary data, Symposium no.48 (2002), Paper No. 1140, $17^{\text {th }}$ WCSS, Thailand, 14-21 August.

[14] JenNy H., Factors of soil formation: A system of Quantitative Pedology, McGraw-Hill (1941), New York.
[15] Kasteel, R., Vogel H.-J. Roth K., From local hydraulic properties to effective transport in soil, European Journal of Soil Science (2000), 51:81-91.

[16] Kim C.P., StRICKeR J.N.M., Influence of spatially variable soil hydraulic properties and rainfall intensity on the water budget, Water Resour. Res. (1996), 32:1699-1712.

[17] KutileK M., Nielsen D.R., Soil hydrology. Catena Verlag, Geosciences Publisher (1994), 370 pp.

[18] Manabe S., Climate and the ocean circulation: 1. The atmospheric circulation and the hydrology of the earth's surface, Mon. Wea. Rev. (1969), 97: 739-774.

[19] Manfreda S., Carriero D., Iacobellis V., Sole A., FiORENTINO M., The effects of soil properties on floods in the Agri Basin (southern Italy), River Basin Management II, ISBN: 1-85312-966-6 (C.A. Brebbia, ed.) (2003), Wessex Institute of Technology Press, UK, pp. 321-330.

[20] Manfreda S., Fiorentino M., IAcobellis V. DREAM: a Distributed model for Runoff, Evapotranspiration, and Antecedent Soil Moisture Simulation, Advances in Geosciences (2005), 2, 31-39.

[21] Minasny B., McBratney A.B., Integral energy as a measure of soil-water availability, Plant Soil (2003), 249, 253-262.

[22] Mualem Y., A new model for predicting the hydraulic conductivity of unsaturated porous media, Water Resour. Res. (1976), 12: 513-522.

[23] PARK S.J., McSweEney K., Lowery B., Identification of the spatial distribution of soils using a processbased terrain characterization, Geoderma (2001), 103: 249-272.

[24] Romano N., SANTINI A., Effectiveness of using pedotransfer functions to quantify the spatial variability of soil water retention characteristics, J. Hydrology (1997), 202: 137-157.

[25] Romano N., Palladino M., Prediction of soil water retention using soil physical data and terrain attributes, Journal of Hydrology (2002), 265: 56-75.

[26] Romano N., Spatial structure of PTF estimates. In "Development of Pedotransfer Functions in Soil Hydrology", Pachepsky Y.A. and. Rawls W.J., eds. Elsevier Science B.V. (2004), pp. 295-319.

[27] Romano N., CHIRICo G.B., The role of terrain analysis in using and developing pedotransfer functions. In "Development of Pedotransfer Functions in Soil Hydrology", Pachepsky Y.A. and Rawls W.J. eds. Elsevier Science B.V. (2004), pp. 273-294.

[28] Romano N., SANTini A., La risposta idrologica dei suoli a diverse scale spaziali. $28^{\circ}$ Convegno di Idraulica e Costruzioni Idrauliche (2004), vol. 6, pp. 165-183, Editoriale Bios, Cosenza (Italy), ISBN 887740-380-2.

[29] Wosten J.H.M., Lilly A., Nemes A., Le Bas C., Development and use of a database of hydraulic properties of European soils, Geoderma (1999), 90: 169-185.

[30] Schulz K., Seppelt R., Zehe E., Vogel H.J., ATTINGER S., Importance of spatial structures in advancing hydrological sciences, Water Resour. Res. (2006), 42, W03S03, doi:10.1029/ 2005WR004301.

[31] Zhu A.X., Band L., Vertessy R., Dutton B., Derivation of soil properties using a soil inference model (SoLIM), Soil. Sci. Am. J. (1997), 61: 523-533. 


\section{SUMMARY}

Land-surface models at basin scale usually employ various combinations of land-use and soil class data to parameterize the major hydrologic processes. Even though soil exerts a major influence on hydrologic processes, soil hydraulic behavior is still difficult to quantify at relatively large scales. Recently soil hydraulic parameterization for hydrologic modeling can be conveniently carried out using pedotransfer rules, which are based on the knowledge of basic soil physical and chemical variables, such as bulk density, textural composition, and organic matter content. However, the availability of this basic information can be rather limited over large land areas. Therefore, in this work we explore the feasibility of employing morphological features to retrieve basic soil data being then used in pedotransfer functions (PTFs), as well as soil depth being viewed here as an indicator of the lower boundary condition. The proposed approach is applied in the Agri River basin (approximately $1770 \mathrm{~km}^{2}$ ), in Southern Italy (Basilicata Region), where we assessed relationships among soil depth and texture with morphological attributes, such as elevation, slope gradient, slope orientation (aspect), and surface curvature. Climatic conditions were defined using mean annual rainfall and climatic indices. The results show an enhanced correlation between soil depth and slope when accounting for the local vegetation types. As expected, texture can be conveniently linked to parent material obtained from lithology. We show an application of the method to derive soil parameters from morphological and vegetation coverage data (DEM, Corine Land Cover, etc.), which are actually available for almost all national basins.

\section{Key words:}

Soil, water, soil depth, hydraulic properties, pedotransfer function, basin scale. 